\title{
Cognition of the Innovation and Entrepreneurship System Among the Different Grades and Genders of Undergraduates in Environmental Science and Engineering Education: A Case Study From Universities in Western China
}

\author{
Jian Zhang, Huanjie Xie, Tianshu Chen and Jianjun Cao*
}

College of Geography and Environmental Science, Northwest Normal University, Lanzhou, Gansu province, China ${ }^{*}$ Corresponding author.Email: caojj@nwnu.edu.cn

\begin{abstract}
The innovation and entrepreneurship education play an important role in higher education system worldwide. However, cognition differences in innovation and entrepreneurship of undergraduates (such as grade, gender) are not well explored. In this study, taking undergraduates engaged in environmental science and engineering education from universities in western China (Gansu and Shaanxi provinces) as an example, the questionnaire survey method was used to study the impact of undergraduates with different grades and genders on cognition of innovation and entrepreneurship. Results showed that with the increase of grades, undergraduates' cognition of the innovation and entrepreneurship was improved, reflecting the improvement of interesting, the degree of support and ability for the innovation and entrepreneurship with the increasing of age. The abilities of independent innovation between male and female undergraduates were significant difference, with the former being lower the latter. This research can provide decision-making basis for the reform of the innovation and entrepreneurship education system in China's universities and colleges.
\end{abstract}

Keywords: Undergraduates, The innovation and entrepreneurship system, Environmental science and engineering education, Cognition, Universities in Western China.

\section{INTRODUCTION}

The innovation and entrepreneurship education (IEE) play an important role in higher education system worldwide. Since at least the fifteenth century, the importance of the IEE to society has been confirmed and discussed, and the debate is still a hot topic [1,2]. After Purdue University held a conference entrepreneurial in 1970 s, many universities in the United States and Canada started to hold annual conferences and seminars on the IEE [3]. At the International Symposium on Education in the 1990s, UNESCO (United Nations Educational, Scientific and Cultural Organization) proposed that IEE is the third education pass that the 21 st century's undergraduates should have in addition to the traditional academic education and vocational educations [4-8], but till now, the development of the IEE has not achieved its original goals [9]. Universities and colleges, as the foundation for talent cultivation, are shouldering the important mission of social-economic development, and thus improving their ability of innovation and entrepreneurship in the process of education and teaching is necessary and urgent [10].

In order to cope with the new opportunities and challenges faced by the new round of technological revolution and industrial transformation in recent years, the Ministry of Education of China proposed the "New Engineering Concept" in 2017. It is an overall reform and innovation of engineering education and has become an inevitable choice for universities to explore engineering education reforms [11]. Environmental science and engineering is an emerging comprehensive interdisciplinary, developing on the basis of natural 
sciences, engineering sciences, and humanities and social sciences with the emergence and evolution of environmental issues and involving a wide range of industries. China's environmental science and engineering education started in the $1970 \mathrm{~s}$, but it has developed extremely rapidly. With Chinese government continues to pay attention to environmental protection, undergraduates not only need a solid theoretical foundation, knowledge, skills and professionalism, but they also require innovation and entrepreneurship under the background of "New Engineering Concept" [12].

However, the differences in cognition of IEE of undergraduates (such as grade, gender) are not well studied, which is not conducive to improving the quality of IEE and cultivating innovative talents for undergraduates [13-14]. Taking undergraduates engaged in environmental science and engineering education from universities in western China (Gansu and Shaanxi provinces) as an example, the questionnaire survey method was used to study difference in cognition of IEE among different grades and between different genders in order to provide a decision-making basis for the reform of the IEE system in China's universities and colleges.

\section{METHODOLOGY}

\subsection{Questionnaire Survey}

In Sep 2020, firstly, 50 questionnaires with open-end were done to modify the draft of the questionnaire and shape the closed-end questionnaire. Secondly, 314 questionnaires were carried out by using on-site and internet survey methods. After excluding incomplete questionnaires, 297 valid questionnaires were recovered.

The questionnaire mainly consists of two parts: the basic information of the respondents (i.e. gender and grade), and cognition of IEE system among the respondents (i.e. interests, degree of support, independent innovation abilities and implementation) (Figure 1).

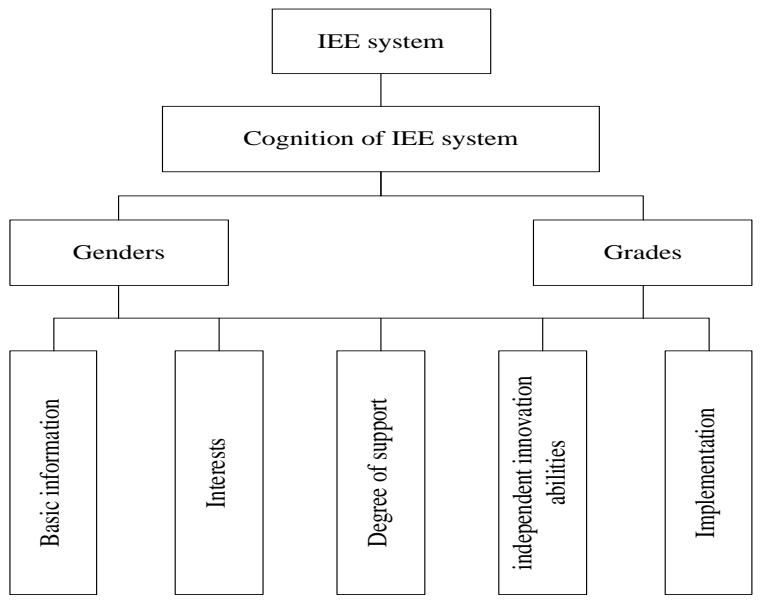

Figure 1 The questionnaire survey of IEE system.

\subsection{Statistics}

Chi-square was used to quantify the differences in cognition of IEE between and among undergraduates with different genders and grades, respectively, by IBM SPSS Statistics 22.0.

\section{RESULTS}

\subsection{Basic Information of the Respondents}

Among the investigated respondents, 141 were males, and 156 were females, accounting for $47.47 \%$ and $52.53 \%$ of the total, respectively; 40 were freshmen, 70 were sophomores, 95 were juniors and 92 were seniors, accounting for $13.47 \%, 23.57 \%, 31.99 \%$, and $30.98 \%$ of the total, respectively. The basic situation of the respondents is shown in Table 1.

Table 1. Basic information of the respondents

\begin{tabular}{|c|c|c|c|}
\hline $\begin{array}{c}\text { Investigation } \\
\text { item }\end{array}$ & Result & Number & Proportion/\% \\
\hline \multirow{2}{*}{ Gender } & Male & 141 & 47.47 \\
\cline { 2 - 4 } & Female & 156 & 52.53 \\
\hline \multirow{4}{*}{ Grade } & Freshman & 40 & 13.47 \\
\cline { 2 - 4 } & Sophomore & 70 & 23.57 \\
\cline { 2 - 4 } & Junior & 95 & 31.99 \\
\cline { 2 - 4 } & Senior & 92 & 30.98 \\
\hline
\end{tabular}

\subsection{Cognition of IEE System of Different Grades on Respondents}

There were significant differences in the degree of interest in IEE system and support for IEE system among different grades of respondents $(\mathrm{P}<0.01)$ (Figure $2 \mathrm{~A}$; Figure $2 \mathrm{~B}$ ), with seniors being the most interested in IEE system and freshmen being the least interested in it, and the degree of support for IEE system of the seniors being the highest while the sophomores being the lowest. Also, there were significant differences in the independent innovation abilities among different grades of respondents $(\mathrm{P}<0.01)$ (Figure $2 \mathrm{C})$. The seniors have the highest independent innovation abilities, while the freshmen have the lowest ones. However, there was no significant differences in the opinions of the implementation of IEE system among different grades of undergraduates $(\mathrm{P}>0.05)$ (Figure 2D), and they all agreed that the IEE implemented by the universities and colleges is generally not good and needs further improvement. 

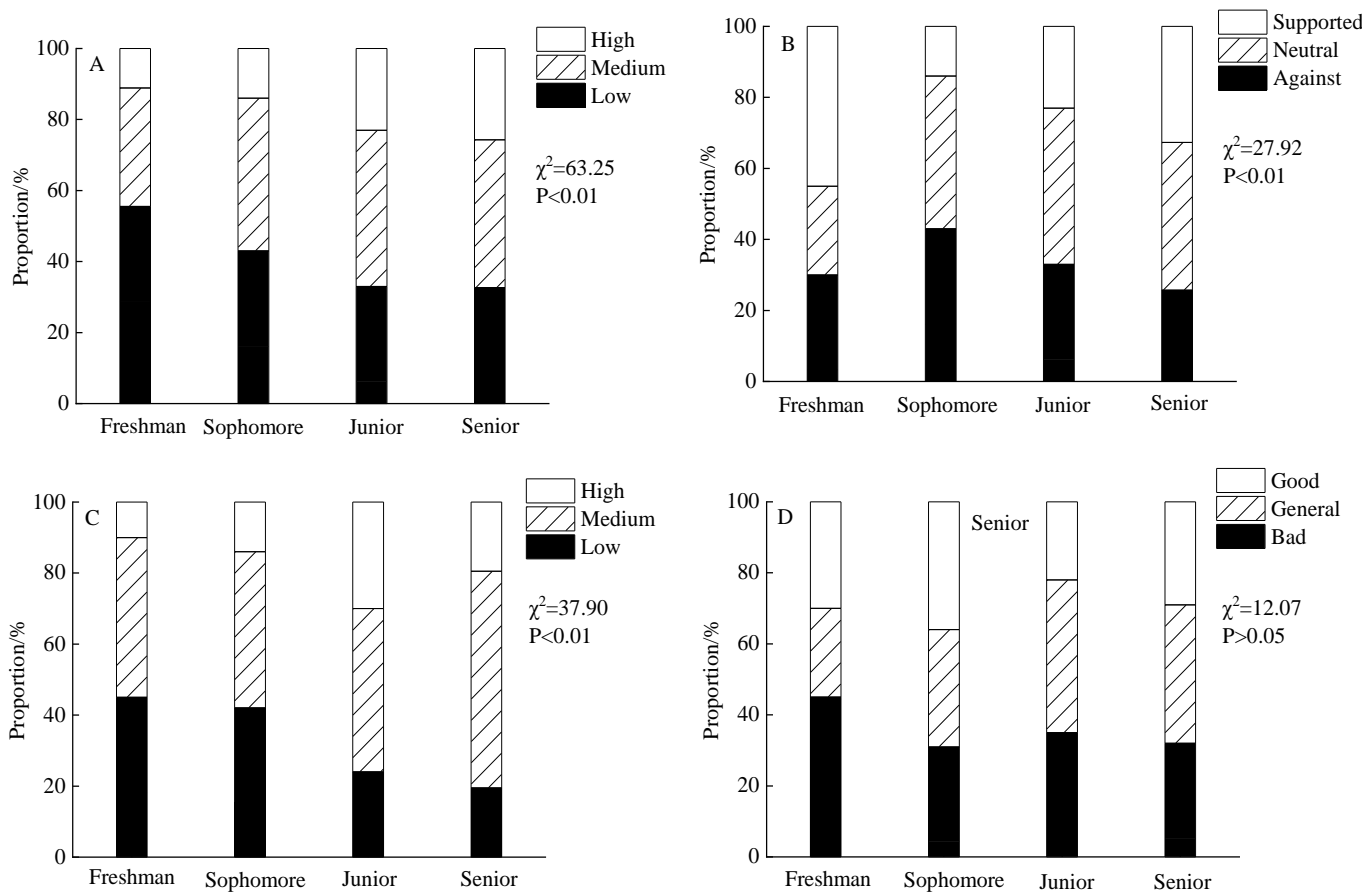

Figure 2 Cognition of IEE system among different grades of the respondents.
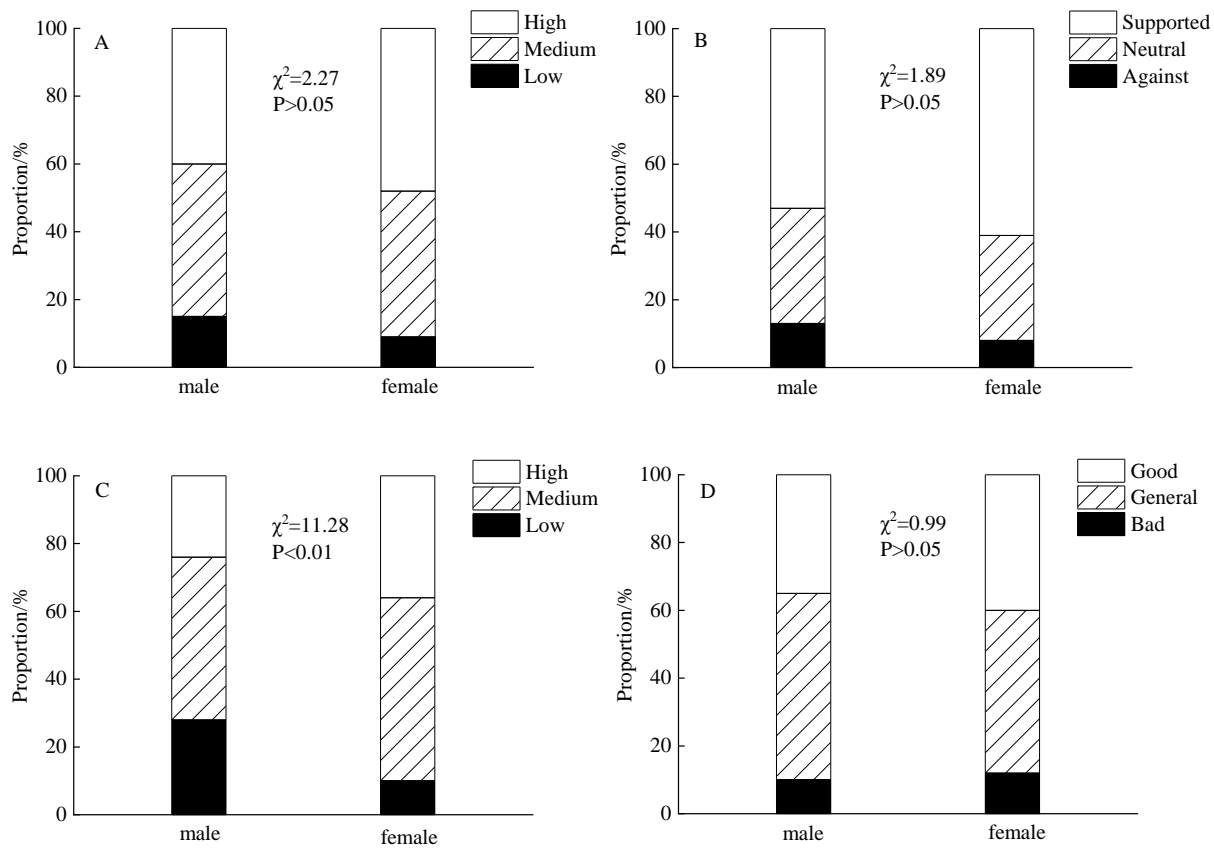

Figure 3 Findings in cognition of IEE system of different genders on respondents.

\subsection{Cognition of IEE System between Males and Females of the Respondents}

There was no significant differences in the degree of interest, the degree of support and the opinions of the implementation of IEE system between different genders of respondents $(\mathrm{P}>0.05)$ (Figure 3A, 3B, 3D), while there were significant differences in the independent innovation ability between them $(\mathrm{P}<0.01)$ (Figure 3C).

\section{DISCUSSIONS}

\subsection{The Influence of Grade on Undergraduates' Cognition of IEE System}

In the present study, seniors and juniors had better cognition of IEE than freshmen and sophomores (Figure 2), suggesting that advanced students has a positive effect on carrying out the IEE [15]. Meantime, higher grades have a clearer cognition in the IEE training project due to the fact that most course teaching system 
requires them to be consolidated and improved by participating in experiments and social practices [16]. Accordingly, seniors and juniors have stronger willingness and greater abilities to join in the IEE project. Furthermore, most of the undergraduates hold a positive support attitude to the IEE system, suggesting that they have an innovation and entrepreneurial intention and a positive feedback on innovation and entrepreneurship [15]. However, all grades generally regarded that the IEE implemented by the universities and colleges is not good, indicating that universities and colleges should pay more attention to the cultivation of undergraduates' interest in innovation and entrepreneurship, and at the same time establish supporting courses and activities in response to the needs of innovation and entrepreneurship by advanced grades to improve their innovation and entrepreneurship capabilities.

\subsection{The Influence of Gender on Undergraduates' Cognition of the IEE System}

As presented in Figure 3, the influence of gender on interest, the degree of support and implementation for IEE system was not obvious. However, the abilities of independent innovation in the IEE between male and female undergraduates were significant difference, with female having greater abilities than male. This may be related to the personality and other personal characteristics of female undergraduates as most of them have correct learning motivation, stable learning emotions, and long-lasting learning behaviors and tenacious learning willingness [17-19]. This also reflects that females, especially contemporary female undergraduates, have a higher sense of crisis and the importance of improving themselves.

\section{CONCLUSIONS}

Grades have larger effect on cognition in the IEE system than genders. This requires the IEE curriculum and targeted reform plans to be diversified by universities and colleges in the future to meet various needs. Meanwhile, universities and colleges need to strengthen the implementation of the IEE, and further explore and reform the IEE curriculum system in terms of cultivating undergraduates' interests and abilities in innovation and entrepreneurship.

\section{AUTHORS' CONTRIBUTIONS}

Jian Zhang and Jianjun Cao designed the research and methodology. Huanjie Xie and Tianshu Chen conducted the questionnaire survey. Huanjie Xie and Tianshu Chen analysed data. Jian Zhang, Huanjie Xie and Tianshu Chen wrote the original draft. All of the authors reviewed the manuscript.

\section{ACKNOWLEDGMENTS}

This work was supported by Research Project of Innovation and Entrepreneurship Education and Teaching Reform for Colleges and Universities in Gansu Province, China (2020).

\section{REFERENCES}

[1] B.A. Kirchhoff, J.D. Linton, S.T. Walsh. NeoMarshallian Equilibrium Versus Schumpeterian Creative Destruction: Its Impact on Business Research and Economic Policy. Journal of Small Business Management, 2013, 51(2), 159-166. DOI: $10.1111 /$ jsbm. 12018

[2] H.B. Zhu, K. Zhang, U.S. Ogbodo. Review on Innovation and Entrepreneurship Education in Chinese Universities during 2010-2015. EURASIA Journal of Mathematics Science and Technology Education, 2017, 13(8), 1305-8215. DOI: 10.12973/eurasia.2017.01042a

[3] K.R. Mcclure. Building the innovative and entrepreneurial university: An institutional case study of administrative academic capitalism. Journal of Higher Education, 2016, 87(4), 516-543. DOI: $10.1353 /$ jhe.2016.0023

[4] X. Xie. Outstanding teacher program in Canada: Objective and path. Global Education. 2016, 45(10), 114-119.

[5] S.S. Li, L.F. Li, H.B. Sun, B. Yang. Building a training system for innovation and entrepreneurship. Tsinuhua Journal of Education, 2017, 38(2), 111-116. DOI: 10.14138/j.10014519.2017.02.011106

[6] H. Zheng. British teaching excellence framework (TEF): Concepts, criteria and enlighten. Studies in Foreign Education, 2017, 44(8), 90-104.

[7] S. Yuan, F. He. The development strategies and inspiration of Harvard School of Engineering and Applied Sciences. Research in Higher Education of Engineering, 2018, (2), 67-70.

[8] S.L. Zhao, H. Zhang, J.L. Wang. Cognition and system construction of civil engineering innovation and entrepreneurship system in emerging engineering education. Cognitive Systems Research, 2018, 52, 1020-1028. DOI: 10.1016/j.cogsys.2018.10.020

[9] G. Barton, P. Lisboa, A. Lees, S. Attfield. Gait quality assessment using self-organising artificial neural networks. Gait \& Posture, 2007, 25(3), 374379. DOI: $10.1016 /$ j.gaitpost.2006.05.003 
[10] Z. Xiao, S.J. Ye, B. Zhong, C.X. Sun. BP neural network with rough set for short term load forecasting. Expert Systems with Applications, 2009, 36(1), 273-279. DOI: 10.1016/j.eswa.2007.09.031

[11] Z.X. Wang. Exploration of innovation and Entrepreneurship Talent Training System under the background of "New Engineering". Guide to Science and Education, 2019, 21(12), 31.

[12] Z.L. Li, R.J. Liao, L.Y. Dong. Specialty construction for the emerging engineering education: Connotation, formation path and training mode. Research in Higher Education of Engineering, 2018, 52(2), 21-24.

[13] B.A. Niccum, A. Sarker, S.J. Wolf. Innovation and entrepreneurship programs in us medical education: a landscape review and thematic analysis. Medical Education Online, 2017, 22(1), 1360722. DOI: 10.1080/10872981.2017.1360722

[14] Z.P. Cao, M. Zhou. Research on the Innovation and Entrepreneurship Education Mode in Colleges and Universities Based on Entrepreneurial Ecosystem Theory. Educational sciences: theory \& practice, 2018, 18(5), 1612-1619. DOI: 10.12738/estp.2018.5.060
[15] J. Zhang, Y.N. Ren, C.Y. Yue. A Survey of College Students' Current Cognition of Entrepreneurial Education - a case study of Shanxi Agricultural University. Social Sciences Journal of Universities in Shanxi, 2019, 31(2), 7378. DOI: 10.16396/j.cnki.sxgxskxb.2019.02.016

[16] Y.Y. Ma. Investigation on Undergraduates' Willingness to Participate in Innovative Practical Projects and Analysis of influencing Factors taking the survey data of Undergraduates of Ningxia University as an example. Innovation and Entrepreneurship Education, 2019, 10(4), 54-59. DOI: cnki:sun:cxyc.0.2019-04-011

[17] J. Li. Analysis on the Factors Affecting College Students' School Record. Journal of Tianjin Adult Higher Learning, 2005, 7(3), 55-59.

[18] Y. Zhou. Probe into Gender Differences of University Students' English Achievement. Journal of Anhui University of Technology (Social Sciences), 2005, 22(3), 87-88.

[19] S.F. Mei, Y.N. Dai. An Analysis of the Influencing Factors of College Students' Classroom Learning Effectiveness. New Education Era, 2016, 44, 73. 